\title{
PARAMETRIC ANALYSIS, DESIGN, EVALUATION AND OPTIMIZATION OF FLAT SLABS AND CONVENTIONAL STRUCTURE
}

\author{
Yadunandan.Yadav.P.N ${ }^{1}$, Pradeep.T.R ${ }^{2}$, Vijayalakshmi Akella ${ }^{3}$ \\ ${ }^{1} P G$ student, Dept. of Civil Engineering, K. S. School of Engineering and Management, Bangalore, Karnataka \\ ${ }^{2} P G$ student, Dept. of Civil Engineering, K. S. School of Engineering and Management, Bangalore, Karnataka \\ ${ }^{3}$ Professor of Head, Dept. of Civil Engineering, K. S. School of Engineering and Management, Bangalore, Karnataka
}

\begin{abstract}
In current century, many construction projects all over the world are going through financial crises because of high financial budgets. To economize the structure, structural optimization techniques should be used. For large projects it is necessary to go for structural optimization because it directly affects cost of construction. In this present study $G+15$ structures is considered and has been analysed using ETABS considering various parameters such as grade of concrete (M25, M30, M35, M40), depth of beams (300x400mm, 300x450mm, 300x500, 300x550mm), depth of slabs (150mm, 175mm, 200mm, 225mm), column size (600x700mm, $600 x 800 \mathrm{~mm}, 600 \times 900 \mathrm{~mm}, 600 \times 1000 \mathrm{~mm})$ and Flat slabs of depth $(150 \mathrm{~mm}, 175 \mathrm{~mm}, 200 \mathrm{~mm}, 225 \mathrm{~mm})$. The cost of the structure is calculated for each of the model. And then it is compared with the other models. The data is incorporated to MATLAB and the polynomial equation is obtained for all the models. The optimum structure elements are then chosen and the cost of the structure is optimized. Based on the study for column $600 x 700 \mathrm{~mm}$, beam $300 \times 550 \mathrm{~mm}$, conventional slab of $150 \mathrm{~mm}$, grade of concrete is M25. The cost of the structure Rs 32,22,707 which is less than all other combination. Based on the study of optimization of flat slab, column size $600 \times 700 \mathrm{~mm}$, beam 300 X $550 \mathrm{~mm}$, slab of $150 \mathrm{~mm}$ and grade of concrete M35. The cost of the structure is Rs 40,97,551 and these are optimized structure combination.
\end{abstract}

Keywords: Optimization, ETABS, MATLAB, SAFE, Flat-slab, Conventional slab. $* * *$

\section{INTRODUCTION}

The origin of optimization technique can be followed since 300 BC and from Cauchy and Newton Lagrange. The advancement of the differential strategies for optimization was conceivable in light of the contribution of Leibnitz and Newton. The base of the calculus varieties were laid by Euler, Weierstrasse, Bernoulli and Lagrange. Optimization is a process of maximizing or minimizing of one or more functions with any possible boundary conditions to obtain effective result.

Civil Engineering is the professional engineering discipline that deals with the design, construction, and maintenance of the physical and naturally built environment. It can be classified as Structural, Water Resources, Transportation and Environmental Engineering as the specialized branches. In all these fields the optimization methods can be applied and are to be taken by designer in each and every step to obtain the cost effective solution in available resources to fulfil the comfort of society is the very purpose of optimization.

Previously Linear, Non- Linear and Dynamic programming methods were used along with their conventional design methods but nowadays the evolutionary optimization methods like Genetic Algorithm, Differential Evolution, Particle Swarm Optimization methods can be used.

Some of these optimization methods are inspired from nature and some by natural processes. Selection of appropriate methods for solving any Civil Engineering problem depends upon the nature of objective function and constraints. Variables can be in continuous or discrete in nature and objective function can be linear or non-linear. They can further be classified as single objective or multiobjective problems.

\section{LITERATURE REVIEW}

Dhananjay D. Joshi at el have discussed in this paper that they had exhibit the utilization of flat plate/slab development in India. They utilized both Indian Standard 456:2000 and American Concrete InstituterACI-312 codes for similar description of flat slab/plate structure outlines. They demonstrated that the utilization of flat slab in office structures gives many points of interest like reduced formwork cost, quick removal and simple establishment. At last they reason that the flat slab/plate can be composed and fabricated either by regular RCC or post-tensioning, yet 
because of a few issues with development in India and its higher cost, ordinary RCC should be preferred decision for spans upto 10 meters. [1]

S. Bari at el have discussed in this paper according to $\mathrm{BNBC} / \mathrm{ACI}$ Code the ratio of longitudinal steel area to gross concrete section is in the range from 0.01 to 0.08 . The common practice is to choose an arbitrary section and check for bending and axial load with a reinforcement ratio of 2$3 \%$. For particular moment and load there is only one section is economical and reinforcement of the section will be optimized. Since the cost of concrete and reinforcement may vary independently, the percentage of reinforcement in the optimized section varies with the price ratio of steel to concrete. Analyzing the present cost ratio of steel and concrete shows column section is optimized at $1 \%$ of reinforcement for low-rise to medium rise building. Use of high strength concrete in the column has an effect of minimizing the cost. Using 5000 psi concrete instead of 3000 psi concrete saves $20-50 \%$ of total cost. For same axial load and moment resisting capacity, a circular column is found to be more costly than a square column. Also, the cost differences between circular and square column increase with the increase in gross area of concrete.[2]

Subodh C. Sharma at el had discussed the optimization of the supports in a rectangular section panel with certain limited edge conditions. In this paper the optimization is proceeded for all arbitrary edge conditions. Each corner panel of slab-spandrel system is developed and optimization of reinforcement is carried out. The expressions of the optimal orthography ratios for the slab panel and also for the section spandrel framework in light of computer analysis are displayed. They have concluded that for a set of values of the edge restraint parameters. The orthography ratio with regard to the positive reinforcement emerges as the main design variable for the optimization of the panel reinforcement. The optimization of the system reinforcement the spandrel beams may have the minimum torsional reinforcement consistent with adequate ductility. [3]

D.C. Charmpis at el had discussed that progressive collapse scenario is the most important factor to be considered because the term progressive collapse refers to large scale damage as a reactions as a result of chain reactions failure. Three scenarios are discussed by artificially removing column-members from the structural system. The results obtained demonstrate the effectiveness of the proposed optimization approach. Of particular importance is the investigation of the variation in the structural cost achieved when collapse resistance constraints are incorporated in the design process. They have concluded this work provided a first look at of the integration of this tool to the design procedures that for composite buildings, showing this way its potentials and weaknesses. The grouping of the columns which was used here was found to provide more cost effective designs than using the same section for all, keeping the required computational time within acceptable limits.[4]

\section{METHODOLOGY}

a) To study the existing literature on parametric analysis, design, evaluation and optimization of column, beam, conventional slab and flat slab structure.

b) To identify the parameters which influence the optimization of structure are beam size, grade of structural elements, column size and depth of the conventional slab and flat slab.

c) Static analysis is performed by using E-TABS software for $(\mathrm{G}+15)$ storey building of grid system, where the span and size of the grid system is same for all the models. Minimum section sizes and minimum reinforcement will be obtained from the analysis.

d) The cost estimation is carried out for structural members like column, beam and conventional slab structure. Hence cost estimation is calculated by using standard rates of concrete and steel for each structural member.

e) The cost comparison will be done to all the 64 models and considering the optimized structural model combination from the 64 model.

\section{EXPERIMENTAL PROGRAM}

Experimental investigation is carried out for total 64 models. The analysis and design is carried out respectively to understand the maximum and minimum cost optimization of structural grid floors system such as columns, beams, conventional slab and flat slab.

The study is to determine the minimum cost optimization of flat slab structures like,

a) The Modal analysis is carried out in equivalent static load analysis.

b) Design guidance for grid floor structures modal is provided in accordance with Indian Codes of Practice IS: 456: 2000. 


\section{Study On Grid Structure Model}

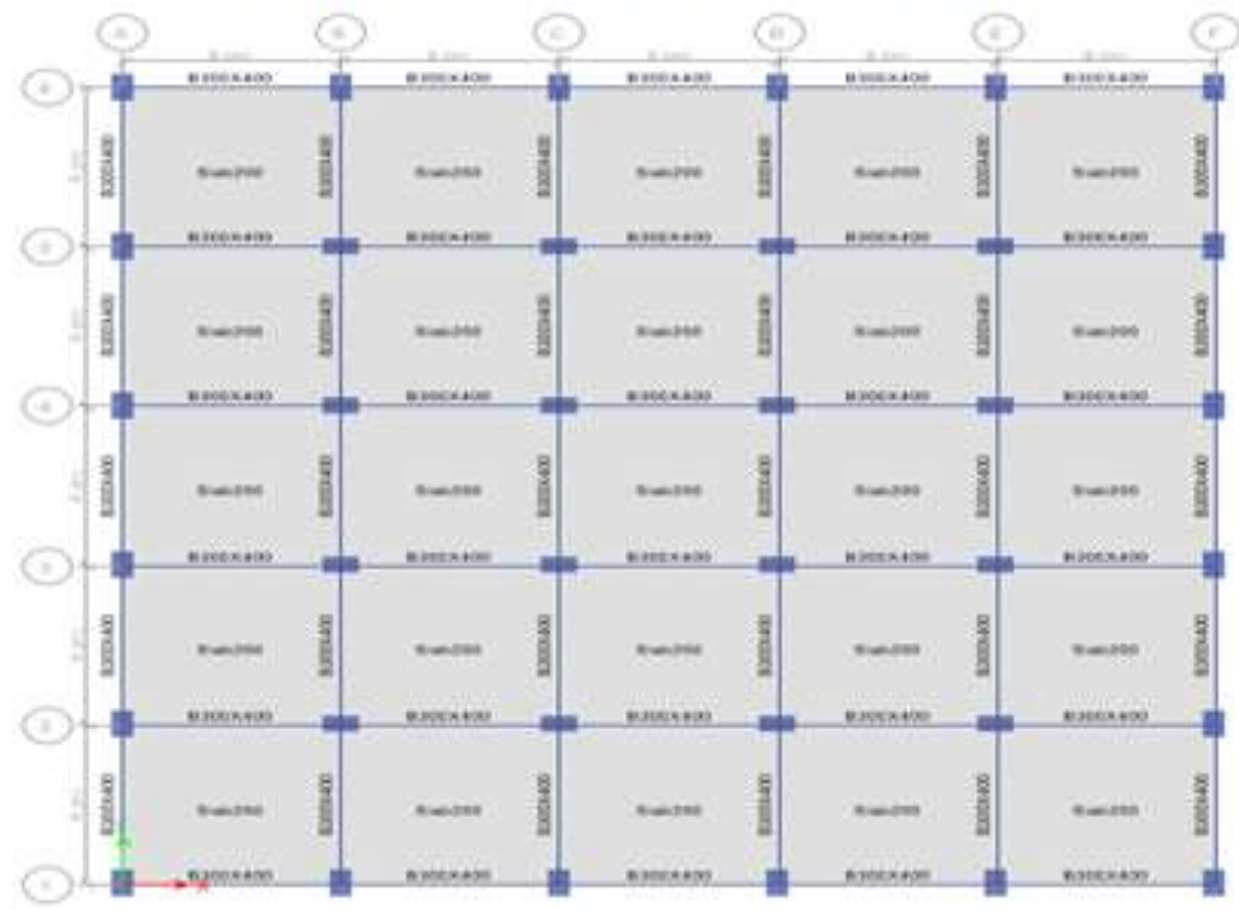

Fig 1: Plan view of study model

\section{3-D MODEL}

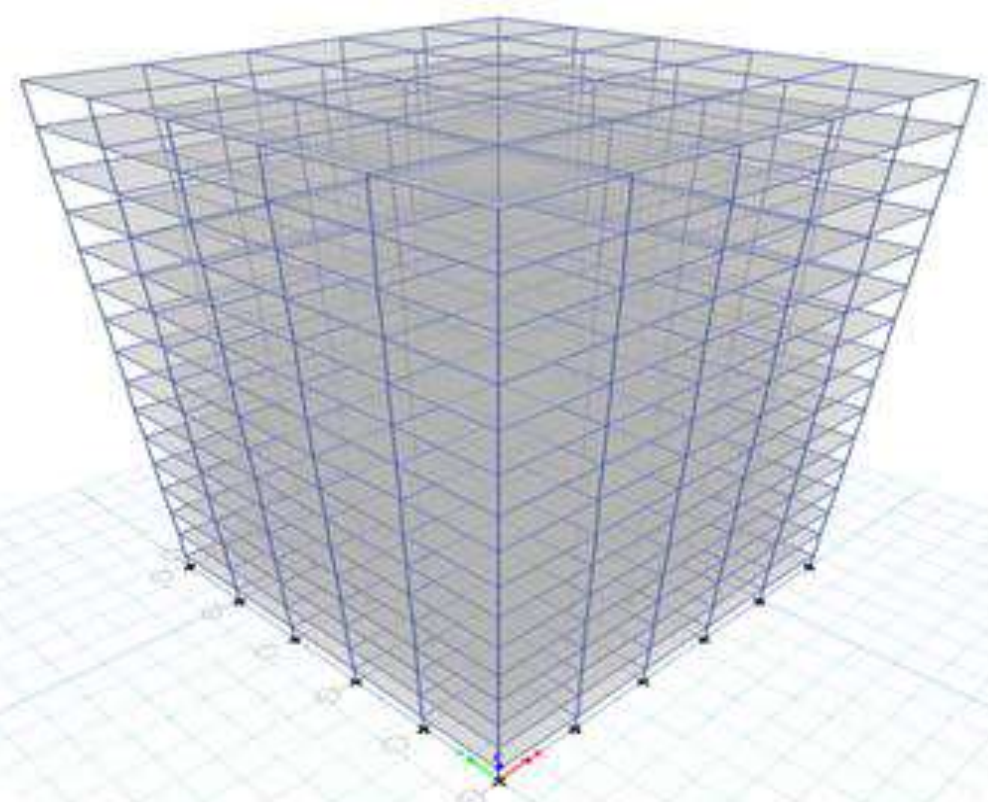

Fig 2: 3D view of study model 


\subsection{Parameter Used}

Table 1: Parameters used for study

\begin{tabular}{|l|l|}
\hline Seismic Zone & 2 \\
\hline Seismic Zone Factor(Z) & 0.1 \\
\hline Importance Factor (I) & 1 \\
\hline $\begin{array}{l}\text { Response Reduction } \\
\text { Factor(R) }\end{array}$ & 3 \\
\hline Soil Type & Medium Soil (Type II) \\
\hline Height of the building & 49.5 \\
\hline Storey to storey Height & 3 \\
\hline Column Sizes & 0.6 X $0.7 \mathrm{~m}^{2}, 0.6$ X 0.8 \\
& $\mathrm{~m}^{2}, 0.6$ X $0.9 \mathrm{~m}^{2}$, \\
& $0.6 \times 1.0 \mathrm{~m}^{2}$ \\
\hline Beam Sizes & $0.3 \times 0.4 \mathrm{~m}^{2}$, \\
& $0.3 \times 0.5 \mathrm{~m}^{2}$ \\
\hline Thickness of Slabs and Flat & $0.15 \mathrm{~m}, 0.175 \mathrm{~m}, 0.2 \mathrm{~m}$, \\
Slab & $0.225 \mathrm{~m}$. \\
\hline Drop panel size & $3 \mathrm{~m} \mathrm{x} \mathrm{3m}$ \\
\hline Live Load, Floor Finish & $2.0 \mathrm{KN} / \mathrm{m}^{2}, 1.5 \mathrm{KN} / \mathrm{m}^{2}$ \\
\hline Material Properties & Grade of Concrete $(\mathrm{fck})$ \\
& M25, M30, M35, M40 \\
& Grade of Steel (fy) \\
\hline
\end{tabular}

\section{RESULTS AND DISCUSSIONS}

Table 2: cost optimization of column

\begin{tabular}{|l|l|l|}
\hline Sl. No & Particulars & model \\
\hline 1 & Span & $6 \mathrm{~m} \times 6 \mathrm{~m}$ \\
\hline 2 & Fck & 25 \\
\hline 3 & Fy & 500 \\
\hline 4 & Size of column & $600 \times 700 \mathrm{~mm}$ \\
\hline 5 & Size of beam & $300 \times 400 \mathrm{~mm}$ \\
\hline 6 & Depth of slab & $150 \mathrm{~mm}$ \\
\hline 7 & $\begin{array}{l}\text { Total cost of } \\
\text { structure }\end{array}$ & 4351429 \\
\hline
\end{tabular}

Table 2 shows the parameters like grade of concrete, size of beams and depth of the slab are kept constant, and size of column is varied.

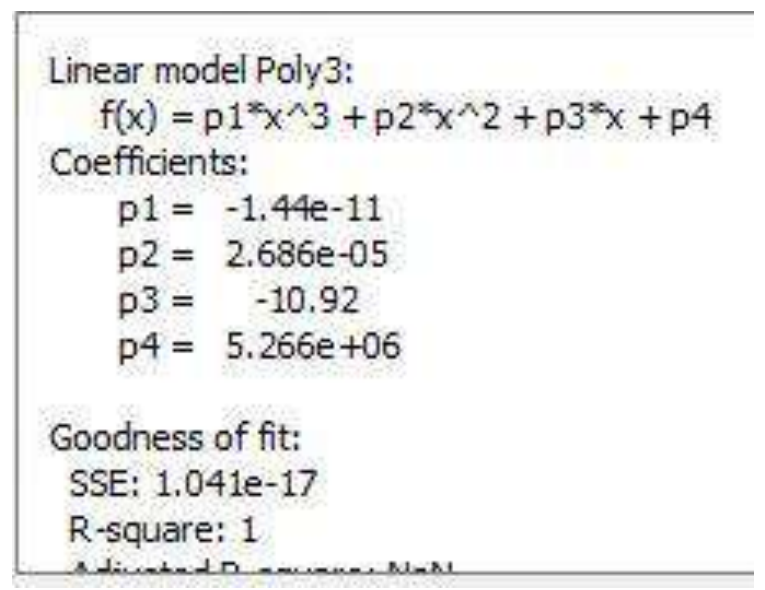

\section{Column size variation}

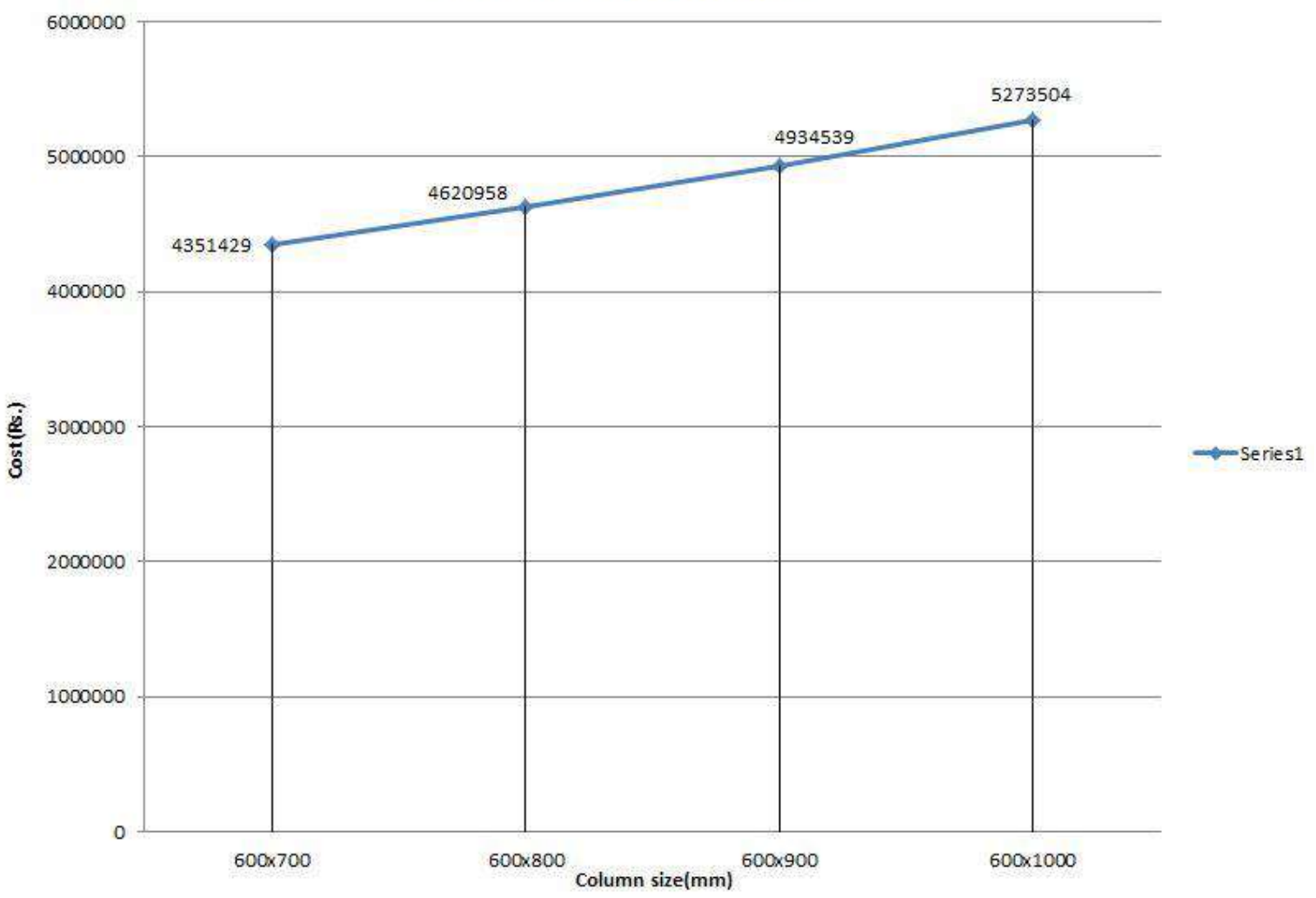

Fig 3: Plot between Column size variation v/s Cost of structure 
Figure 3 is a Plot between Column size variation v/s Cost of structure which shows that the relation between cost and variation in column size. For a fixed grade of concrete M25 with $300 \times 400 \mathrm{~mm}$ size of beam, slab depth is $200 \mathrm{~mm}$ and column size is varied from $600 \times 700,600 \times 800,600 \times 900$ and $600 \times 1000 \mathrm{~mm}$. The size of column is fixed from static analysis of the model using ETABS.

It was observed that as the size of the column increases the cost also increases. There is a positive correlation between the two parameters. This is due to increase in size of the column and which can be attributed to the increase in the quantity of concrete.

Table 3: cost optimization of beam

\begin{tabular}{|l|l|l|}
\hline Sl. No & Particulars & model \\
\hline 1 & Span & $6 \mathrm{~m} \times 6 \mathrm{~m}$ \\
\hline 2 & fck & 25 \\
\hline 3 & fy & 500 \\
\hline 4 & Size of column & $600 \times 700 \mathrm{~mm}$ \\
\hline 5 & Size of beam & $300 \times 550 \mathrm{~mm}$ \\
\hline 6 & Depth of slab & $150 \mathrm{~mm}$ \\
\hline 7 & Total cost of structure & 3782350 \\
\hline
\end{tabular}

\section{Beam Size variation}

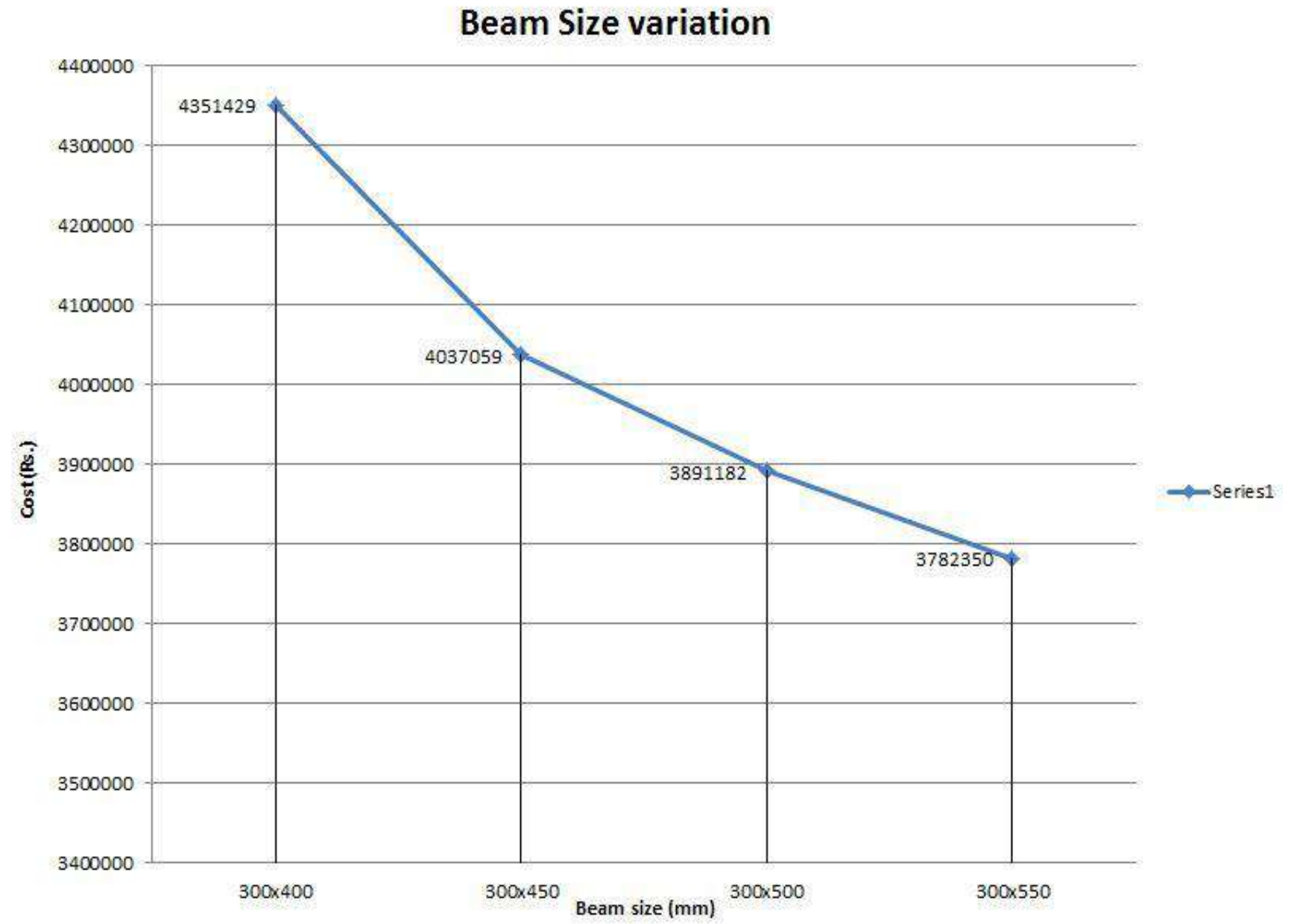

Fig 4: Plot between Beam size variation v/s Cost of the structure
Table 3 shows the parameters like size of column, depth of slab and grade of concrete M25 are kept constant, and size of the beam is varied.

Linear model Poly3:

$$
f(x)=p 1^{*} x^{\wedge} 3+p 2^{*} x^{\wedge} 2+p 3^{*} x+p 4
$$

Coefficients:

$$
\begin{aligned}
& p 1=-6.491 e-09 \\
& p 2=0.003003 \\
& p 3=-469.9 \\
& p 4=2.871 e+07
\end{aligned}
$$

\section{Goodness of fit:}

SSE: $6.661 \mathrm{e}-16$

\section{R-square: 1}


Figure 4 is a Plot between Beam size variation v/s Cost of the structure which shows that the relation between cost and beam area variation. For a fixed grade of concrete of M25 with column size of $600 \times 700 \mathrm{~mm}$ and $200 \mathrm{~mm}$ constant depth of slab and beam sizes are varied from 300x400, $300 \times 450,300 \times 500$ and 300x550 mm. The size of the beam is fixed from static analysis of the model using ETABS.

It was observed that as the beam size increases for this combination the cost decreases. There is a negative correlation between the two parameters. This is due to decrease in steel area.

Table 5: cost optimization of slab

\begin{tabular}{|l|l|l|}
\hline Sl. No & Particulars & model \\
\hline 1 & Span & $6 \mathrm{~m} \times 6 \mathrm{~m}$ \\
\hline 2 & Fck & 25 \\
\hline 3 & Fy & 500 \\
\hline 4 & Size of column & $600 \times 700 \mathrm{~mm}$ \\
\hline 5 & Size of beam & $300 \times 400 \mathrm{~mm}$ \\
\hline 6 & Depth of slab & $150 \mathrm{~mm}$ \\
\hline 7 & $\begin{array}{l}\text { Total cost of } \\
\text { structure }\end{array}$ & 3943556 \\
\hline
\end{tabular}

Table 5 shows the parameters like size of column, grade of concrete and size of beams are kept constant, and depth of slab is varied.

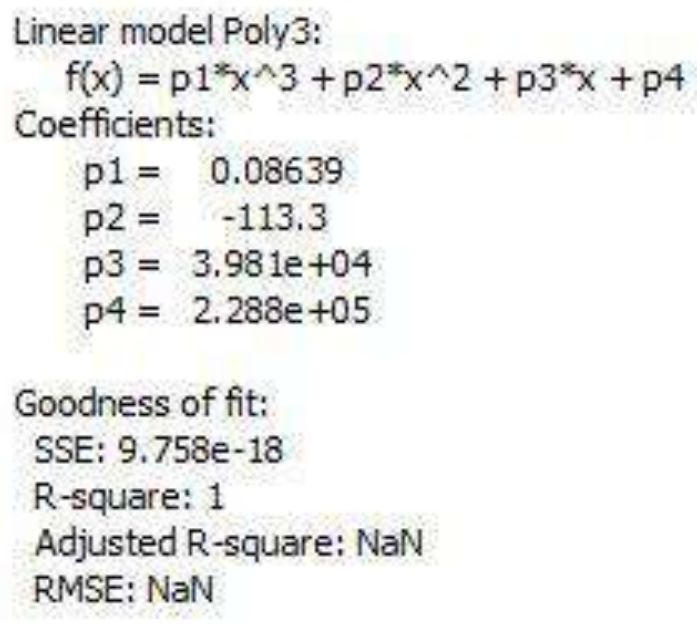

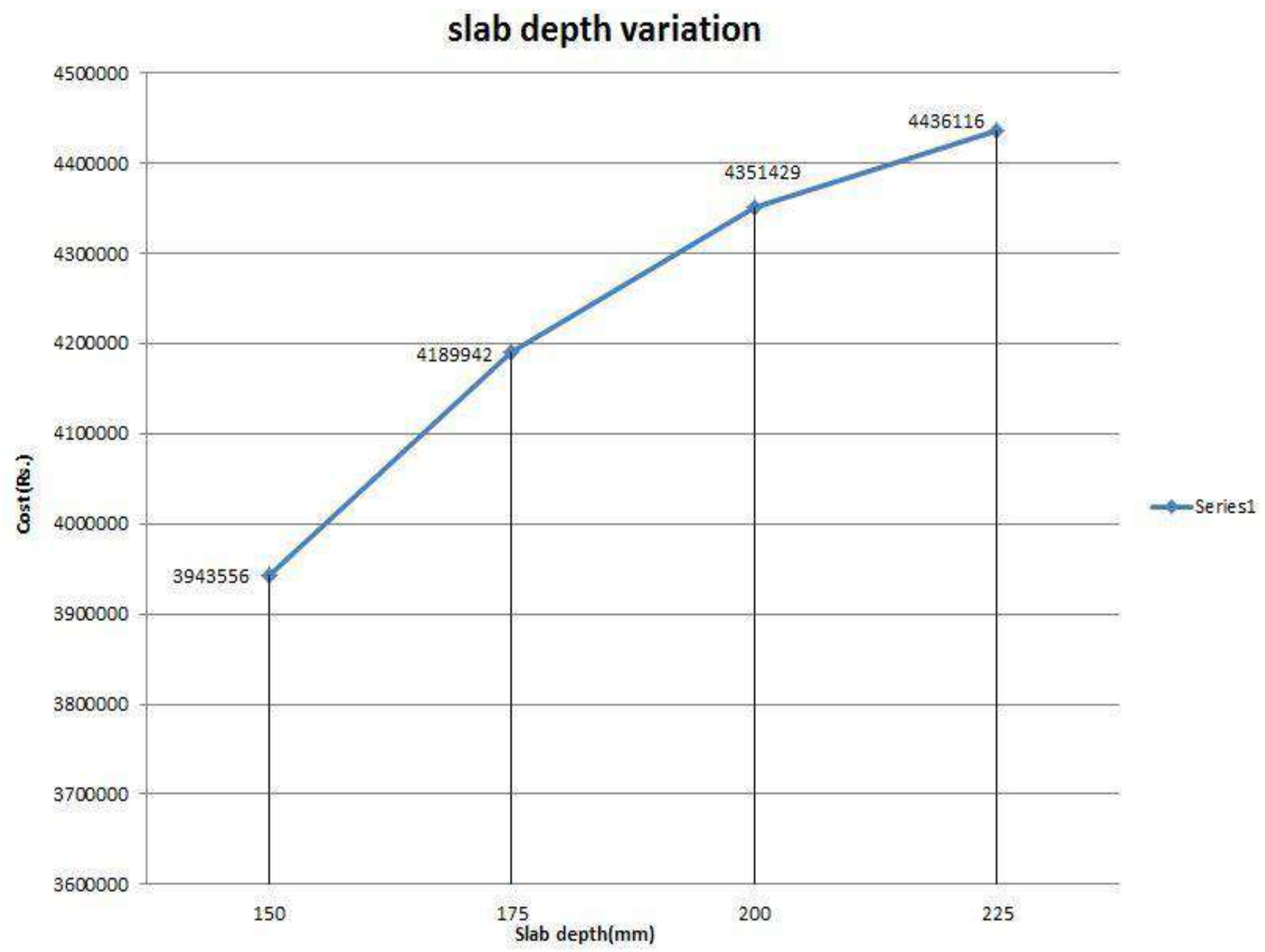

Fig 5: Plot between Slab size variation v/s Cost of structure 
Figure 5 is a Plot between Slab size variation v/s Cost of structure which shows that the relation between cost and variation in slabs depth. For a fixed grade of concrete M25 with columns of $600 \times 700 \mathrm{~mm}$ and $300 \times 400 \mathrm{~mm}$ size of beam and slab depths are varied from 150, 175, 200 and 225 $\mathrm{mm}$. The depth of the slab is fixed from static analysis of the model using ETABS.

It was observed that as the depth of the slab increases the cost also increases. There is a positive correlation between the two parameters. This is due to increase in depth of slab and which can be attributed to the increase in the quantity of concrete.

Table 6: cost optimization of flat slab

\begin{tabular}{|l|l|l|}
\hline Sl. No & Particulars & model \\
\hline 1 & Span & $6 \mathrm{~m} \times 6 \mathrm{~m}$ \\
\hline 2 & Fck & 35 \\
\hline 3 & Fy & 500 \\
\hline 4 & Size of column & $600 \times 700 \mathrm{~mm}$ \\
\hline 5 & Size of beam & $400 \times 500 \mathrm{~mm}$ \\
\hline 6 & Depth of slab & $150 \mathrm{~mm}$ \\
\hline 7 & Total cost of structure & 4227405 \\
\hline
\end{tabular}

Table 6 shows the parameters like size of column, grade of concrete and size of beams are kept constant, and parameter depth of slab is varied.

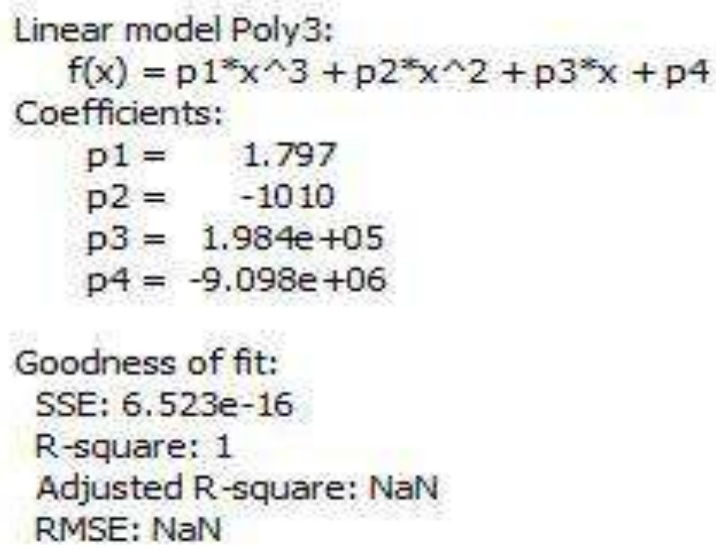

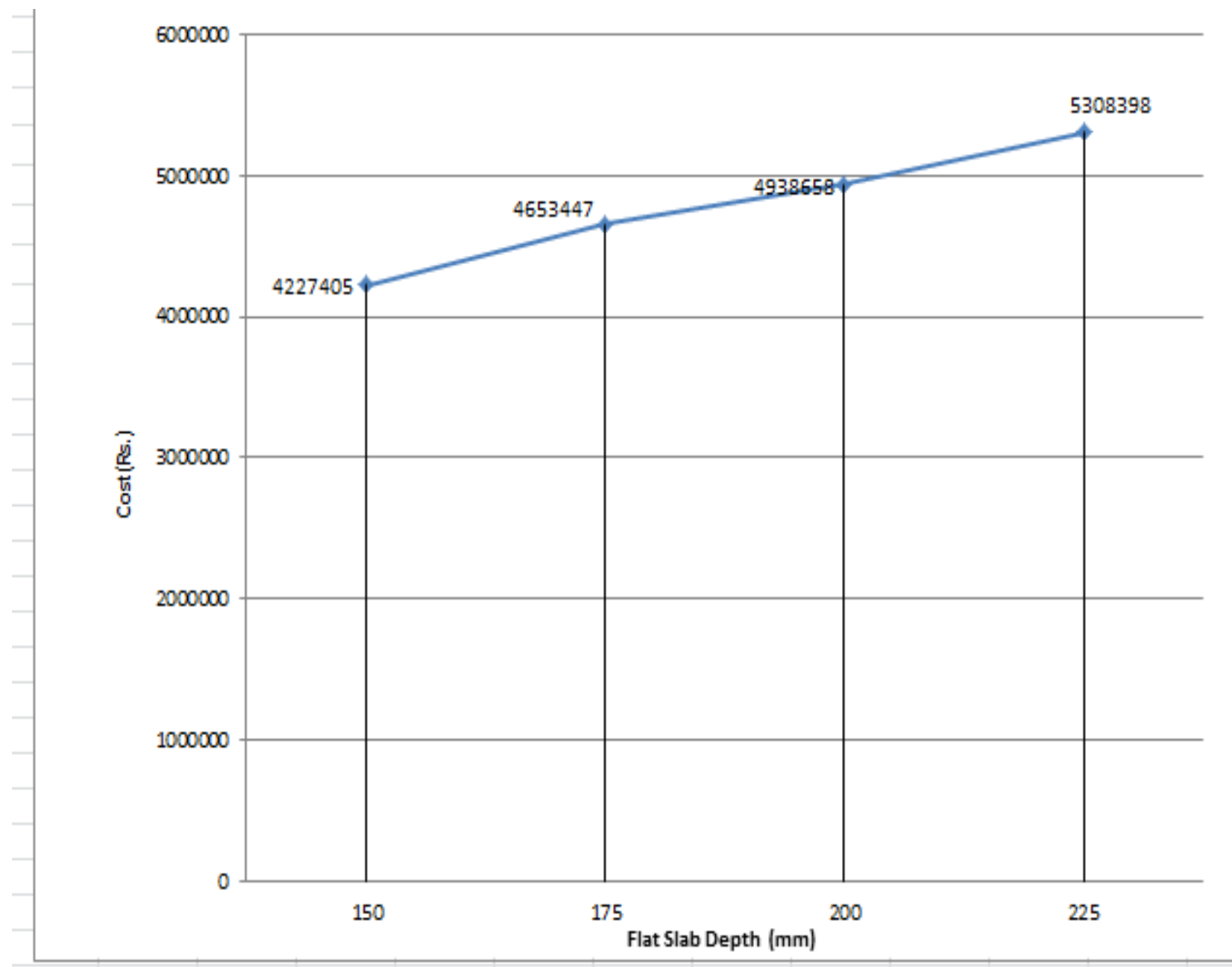

Fig 6: Plot between Slab size variation v/s Cost of structure 
Figure 6 is a Plot between Slab size variation v/s Cost of structure which shows that the relation between cost and variation in slabs depth. For a fixed grade of concrete M25 with columns of $600 \times 700 \mathrm{~mm}$ and $400 \times 500 \mathrm{~mm}$ size of beam and slab depths are varied from 150, 175, 200 and 225 $\mathrm{mm}$. The depth of the slab is fixed from static analysis of the model using ETABS.

It was observed that as the depth of the slab increases the cost also increases. There is a positive correlation between the two parameters. This is due to increase in depth of slab and which can be attributed to the increase in the quantity of concrete

\section{The Final Cost Optimization of Structures}

\begin{tabular}{|l|l|l|}
\hline Sl. no & Particulars & model \\
\hline 1 & Span & $6 \mathrm{~m} \mathrm{x} \mathrm{6m}$ \\
\hline 2 & Fck & 25 \\
\hline 3 & Fy & 500 \\
\hline 4 & Size of column & $600 \times 700 \mathrm{~mm}$ \\
\hline 5 & Size of beam & $300 \times 550 \mathrm{~mm}$ \\
\hline 6 & Depth of slab & $150 \mathrm{~mm}$ \\
\hline 7 & Total cost of structure & 3222707 \\
\hline
\end{tabular}

\begin{tabular}{|l|l|l|}
\hline S1. no & Particulars & model \\
\hline 1 & Span & $6 \mathrm{~m} \times 6 \mathrm{~m}$ \\
\hline 2 & Fck & 35 \\
\hline 3 & Fy & 500 \\
\hline 4 & Size of column & $600 \times 700 \mathrm{~mm}$ \\
\hline 5 & Size of beam & $300 \times 550 \mathrm{~mm}$ \\
\hline 6 & Depth of slab & $150 \mathrm{~mm}$ \\
\hline 7 & Total cost of structure & 4097551 \\
\hline
\end{tabular}

\section{ACKNOWLDEGEMENT}

The author wish to place on record the help provided by the management and the academic teaching and non-teaching faculties of K S School of Engineering and Management, in the completion of this study.

We take pleasure in expressing our sincere thanks to Dr. S. N. Sridhara, principal, K.S. School of Engineering and Management, Bengaluru.

\section{CONCLUSION}

Based on the analysis and design results are obtained in the present investigation of cost optimization in the research work and possible scope of future research work. Dimension of column, beams and slabs are varied. Grades of concrete of M25, M30, M35 and M40 are considered for the study. When one variable like size of the column is varied other variables are kept constant the following conclusions can be drawn.

- Column size of $600 \times 700 \mathrm{~mm}$ is found to be more economical by keeping all other variables constant. For column size $600 \times 700 \mathrm{~mm}$ of M25 grade of concrete the cost of the structure was found to be Rs 43,51,429.
- Beam size of $300 \times 550 \mathrm{~mm}$ is found to be more economical by keeping all other variables constant. For beam size 300 X $550 \mathrm{~mm}$ of M25 grade of concrete the cost of the structure was found to be Rs $37,82,350$.

- Slab depth of $150 \mathrm{~mm}$ is found to be more economical by keeping all other variables constant. For slab of depth $150 \mathrm{~mm}$ of M25 grade of concrete the cost of structure was found to be Rs 39,43,556.

- Flat slab depth of $150 \mathrm{~mm}$ is found to be more economical by keeping all other variables constant. For slab of depth $150 \mathrm{~mm}$ of M35 grade of concrete the cost of structure was found to be Rs 42,27,405.

- $\quad$ Based on the study for column $600 \times 700 \mathrm{~mm}$, beam $300 \times 550 \mathrm{~mm}$, slab of $150 \mathrm{~mm}$, grade of concrete is M25. The cost of the structure Rs 32,22,707 which is less than all other combination.

- Based on the study for column 600 X $700 \mathrm{~mm}$, beam 400 X $500 \mathrm{~mm}$, flat slab of $150 \mathrm{~mm}$, grade of concrete is M35. The cost of the structure Rs 40,97,551 which is less than all other combination.

\section{REFERENCES}

[1] Dr. Pranesh B. murnal Dhananjay D. Joshi, "Performance of flat slab structure using pushover analysis," IOSR journal of mechanical and civil engineering, vol. 8, no. 3, pp. 41-44, september 2013.

[2] A.A. Mamun S. Bari, "Cost optimization of column," international journal of advanced structures and geotechnical engineering, vol. 3, no. 3, pp. 228-233, july 2014.

[3] Subodh C. sharma and Ganpat S. Pandit, "Optimum reinforcement in Spandrel support slab," vol. 1, no. 3, pp. 2293-2306, 1988.

[4] G.S. Papavasileiou and D.C. Charmpis, "Design optimization steel-concrete composite structures with requirements on progressive collapse resistance," vol. 8, no. 3, pp. 53-61, 2102.

[5] Ibrahim M. Mahdi and Ehab Solian Khaled Alreshaid, "Cost optimization of reinforced concrete elemnts," asian journal of engineering, vol. 5, no. 34, pp. 161-174, 2004.

[6] Shubhangi M. Nikate Prakarsh A. Sangave, "A Study on Structural Optimization of Multistoried RCC Buildings," International Journal of Engineering Research and General Science, vol. 3, no. 3, pp. 326353, May-June 2015. 